\title{
3D Filmmaking for User-Selective UHD Stereoscopic Media System: A Case Study on the Film The Old, the New and the Other
}

\author{
Minchol Cha ${ }^{*}$, Alaric Hamacher ${ }^{2}$, Sébastien Simon ${ }^{3}$
}

\begin{abstract}
Despite skepticism about commercial potential, the stereoscopic 3D cinema is still a form that any filmmaker can choose to employ for its aesthetics and its immersive potential. Based on a haptic illusion, the stereoscopic media content requires a new perspective different from the principle of 2D media content in terms of creation and acceptance. This paper examines the technical and aesthetic issues of stereoscopic 3D film production from the perspective of today's emerging realistic and immersive media through a case study. One of the key factors for successful content creation and research and development in stereoscopic 3D cinema is the combination of artistic principles together with technical mastering of the new image technology. The purpose of this paper is to outline the principal challenges and research topics in stereoscopic 3D cinema through a case study of stereoscopic 3D pilot film production for the 'User-Selective UHD Stereoscopic Media Service Platform' of the ETRI (Electronics and Telecommunications Research Institute). This paper intends to examine stereoscopic 3D filmmaking workflow and production methodologies, as well as technical elements and aesthetic issues.
\end{abstract}

Key Words: Haptic Illusion, Realistic \& Immersive Media, Stereoscopic 3D Cinema, User-Selective UHD Stereoscopic Media.

\section{INTRODUCTION}

The history of stereoscopic media dates back to the concept of stereoscopic vision called 'Da Vinci Stereopsis' proposed by Leonardo da Vinci in the 17th century. He explained in A Treatise on Painting (1632) that a given object occludes different parts of the background when viewed from the left eye as compared to the right eye. 'Da Vinci Stereopsis' now refers to depth perception based on the occlusion geometry in the two eyes. This term was introduced by K. Nakayama and S. Shimojo in 1990 [1].

Then stereoscopic media began to develop with the invention of the 'Stereoscope' by Charles Wheatstone in the early 1830s. From about the mid-1850s through the early years of the 20th century, stereoscopic photographic views ('Stereographs') were immensely popular in the United States and Europe and various stereoscopic cameras were developed. Since then, researches on stereoscopic media has been carried out from various perspectives in various fields, such as David Brewster's 'Lenticular Stereoscope' in 1849, Joseph D'Almeida's 'Anaglyph' in 1858, Frederic Eugene Ives' 'Parallax Stereogram' in 1903, and Emmet Leith's 'Holography' in 1962, etc.
On the other hand, the cinema, officially invented by the Lumière brothers in France in 1895, has passed through more than a century of history, leading the visual arts of mankind during the 20th century. In general, the history of stereoscopic cinema has not been dealt with as a major factor in the history of cinema. This phenomenon of marginalization of stereoscopic cinema is due to the fact that the Lumière-type cinema system based on the projection of a flat square screen has become the standard of the global film industry.

In the history of cinema for more than a century, threedimensional stereoscopic films are not prominent, but they have expanded their trajectory of development through various attempts and experiments. For example, the first 'Camera Rig' was invented in 1900, Anaglyph 3D moving images were introduced at the 1900 Paris Exposition, and on June 10, 1915, at the Astor Theater in New York, Edwin S. Porter and William E. Waddell attempted the first public screening of their stereoscopic footage. "The first documented exhibition of a stereoscopic motion picture took place on the morning of June 10,1915 at the Astor Theater in New York. Three reels of test footage by Edwin S. Porter and William E. Waddell were presented in $\mathrm{red} /$ green anaglyphic 3-D. Shown were rural scenes and

\footnotetext{
Manuscript received November 21, 2021; Revised December 26, 2021; Accepted December 30, 2021. (ID No. JMIS-21M-11-040)

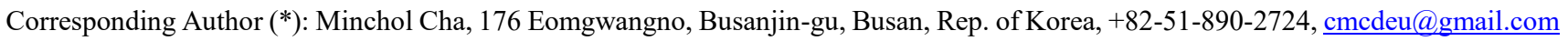

${ }^{1}$ Dept. of Film Studies, Dong-eui University, Busan, Rep. of Korea, cmcdeu@gmail.com

${ }^{2}$ Graduate School of Smart Convergence, Kwangwoon University, Seoul, Rep. of Korea, stereo3d@kw.ac.kr

${ }^{3}$ International College Animation \& VFX Major, Dongseo University, Busan, Rep. of Korea, simonstruous@gmail.com
} 
footage of Niagara Falls, along with an Oriental dancer and specially-filmed 3-D demo sequences from Jim the Penman with John Mason and The Morals of Marcus with Marie Doro. Shortly after the screening, several articles mentioned blurry images during fast movement. Apparently the footage was shown interlocked on two $35 \mathrm{~mm}$ projectors that were either out-of-sync or some segments were photographed with the camera shutters severely out-of-phase."[2] And the first commercial 3D film The Power of Love, released in 1922, had its technical limitations.

In the 1950s, so-called 'Golden Age of Stereoscopic Cinema', more than 70 3D films were released in the United States. In the 1980s, 3D films produced by IMAX appeared, and in the 2000s, stereoscopic cinema met a renaissance thanks to the development of digital technology. In particular, James Cameron's 2009 film Avatar once again confirmed the possibility of 3D cinema. The success of 3D films following the release of Avatar caused a great change not only in the film industry but also in the related fields.

In the past years, a lot of progress has been made in the field of digital image processing and constantly improving technologies in cinema, television, but also in realistic and immersive media such as VR, AR, MR, XR as well as stereoscopic cinema. The digital technology accelerated from the 1980s acted as an important driving force for the rapid development of stereoscopic cinema that continued until the 2000s. With the rapid development of ICT and new technology, stereoscopic media technology is developing in a new direction. In other words, recently, stereoscopic media is moving toward encompassing various orientations such as presence, immersion, and interactivity.

Stereoscopic media is the field with the longest history in the field of realistic and immersive media (content) and its concept was established over a century ago. It can be said that stereoscopic media has entered the stabilization phase from a technological point of view. However, stereoscopic media is currently expanding its scope by combining with XR and interactive media, which include AR, VR, and MR. Therefore, it is required to redefine the concept of stereoscopic media, which has entered a new level of production and utilization that converges with various new technologies.

One of the key factors for successful content creation and research and development in stereoscopic 3D cinema is the combination of artistic principles together with technical mastering of the new image technology. The combination of these fields is of biggest importance to promote and establish the new technologies among creative artists and directors of the movie industry as well as technical crew and distribution businesses. The purpose of this paper is to outline the principal challenges and research topics in stereoscopic 3D cinema through a case study of stereoscopic 3D pilot film production for the 'User-Selective UHD Stereoscopic Media Service Platform' of the ETRI (Electronics and Telecommunications Research Institute). This paper intends to examine stereoscopic 3D filmmaking workflow and production methodologies, as well as technical elements and aesthetic issues.

\section{RELATED WORKS}

According to Frédéric Devernay and Paul Beardsley, stereoscopic cinema brought many new problems that were not addressed by traditional filmmaking. Many of these problems deal with geometric considerations: how to place the two cameras with respect to each other, where to place the actors, what camera parameters (focal length, depth of field) should be used. As a matter of fact, many of these problems were somehow solved by experience, but opinions often diverged on the right solution to film in stereoscopy [3].

Researches and discussions on stereoscopic cinema have been conducted from epistemological, theoretical, technical and aesthetic point of view. "Basic principles of the threedimensional film" [4] published in 1952 is the first theoretical essay on stereoscopic cinema. The authors made a great effort to formalize the influence of the camera geometry on the 3-D perception by the audience, and also proposed a solution on the difficult problem of transitions between shots. Their scientific approach of stereoscopic cinema imposed very strict rules on filmmaking, and most of the stereoscopic filmmakers didn't think it was the right way to go [5].

In 1982, Lenny Lipton, a pioneer in projected threedimensional imagery, founder of the StereoGraphics Corporation and inventor of the CrystalEyes electronic shutter glasses and ZScreen, described the scientific foundations of stereoscopic cinema in his definitive treatment of the subject, Foundations of the Stereoscopic Cinema [6]. Lipton's approach is more viewer-centric, and he focused more on how the human visual system perceives $3 \mathrm{D}$, and how it reacts to stereoscopic films projected on a movie screen [7].

3D Movie Making: Stereoscopic Digital Cinema from Script to Screen [8] written by Bernard Mendiburu in 2009 is one of the best technical introductions to stereoscopic cinema. As a reference by the filmmaking community, this book formalizes stereoscopic filmmaking with clear drawings of the complicated geometric effects involved in. 
Researches on 3D cinema has been actively conducted since Avatar's worldwide box office success in 2009 the release of Avatar in 2009, but within a short time, accelerated development of various realistic and immersive media technologies such as VR, AR, MR, XR has led to a shift in research on stereoscopic media from a more comprehensive perspective that goes beyond 3D cinema. Since the mid-2010s, recent studies have shifted their center of gravity to realistic media or immersive content as if reflecting that the heyday of 3D cinema has passed.

As in this paper, it presented a study on the stereoscopic 3D film production technique through a case study. It investigates the possibilities of the using the $3 \mathrm{D}$ stereoscopic principles such as the I.O.D, convergence point, parallax and the $3 \mathrm{D}$ comfort zone in directing stereoscopic 3D film with the example of stereoscopic 3D short film [9].

One of the recent studies presented strategies for improving stereoscopic content in virtual reality with analyzing the differences between stereoscopy and virtual reality [10].

\section{CASE STUDY: STERESCOPIC 3D FILM PROJECT THE OLD, THE NEW AND THE OTHER}

\subsection{Film Informations, Cast and Crew}

The Old, the New and the Other

2021 | Docufiction | 15 minutes | South Korea | 4K-3D \& Super $8 \mathrm{~mm} \mid$ English subtitles

Starring: Youngjoon Kim, Forest Ian Etsler

Executive Producer: Minchol Cha

Director/Writer/Editor: Sébastien Simon

Director of Stereoscopy: Alaric Hamacher

Director of Photography: Jongyeol Kim

Camera Operator: Hyojun Shin

Camera Assistant: Janghoon Choi

Focus Puller: Dongik Kim

Data Wrangler: Hyeonwoo Jeong

Assistant Director: Junseong Lee

Super 8mm Images: Forest Ian Etsler, Sébastien Simon

Super 8mm Development: Byeongwon Jeon, Hyeonwoo Jeong, Pip Chodorov

On-Set Extras: Kwak Seokhwan, Elisa Adriana, Shi Siwen,

Wang Chuxuan, Zhang Kaicheng

English Translation: Jeongmin Lee

Presented by ETRI (Electronics and Telecommunications Research Institute)
3D camera, equipment \& services provided by Dike Co., Ltd.

Super $8 \mathrm{~mm}$ camera \& services provided by DCTI (Cinema \& Transmedia Institute of Dong-eui University)

Post-production facility provided by DREAM STATION of Dong-eui University

Shot on location in Mipo-Dalmaji, Haeundae district, Busan (Fig. 1)

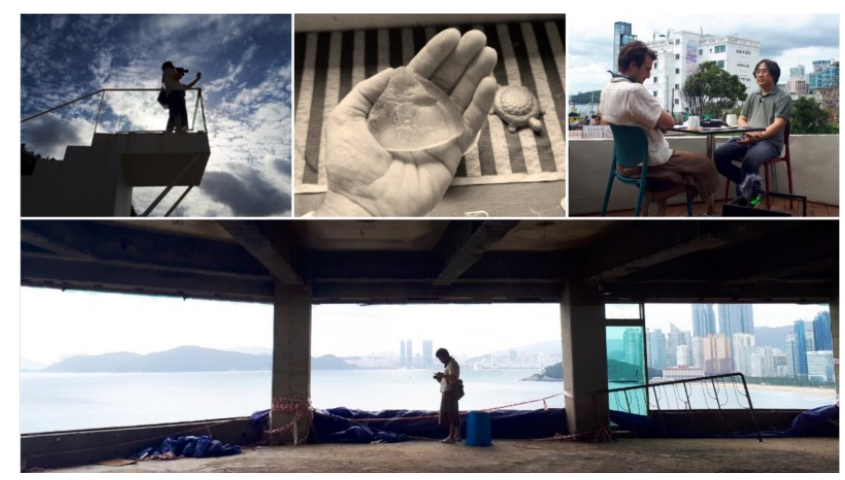

Fig. 1. Still Images from The Old, the New and the Other.

\subsection{Note of Intention}

Even for a city which self-branded as "dynamic", Busan has recently been experiencing some radically abrupt changes in the Mipo-Dalmaji area, symbolized by the already-iconic Haeundae Blueline Park and LCT Towers. Originally intended as a technology showcase, and while still satisfying that requirement, this project also became an attempt to document these changes.

On a purely visual level, the strong horizontality of the train tracks and the imposing verticality of the tower appear as natural extensions of each other. Too-new in a neighborhood which for decades had seen little development, these modern constructions stick out even more. Economically, they are accelerating the gentrification of this area tremendously, sparking the ire of the residents of the area, which is now essentially a giant photo-zone aimed at tourists.

This is why we came to realize that stereoscopic $3 \mathrm{D}$ would be the perfect format for this particular idea: by seemingly 'detaching' layers within the image, it would reflect the fact that these various urban strata (the old neighborhood, the new buildings, the reconstruction sites) are forcibly superimposed on top of each other rather than harmoniously meshed together. Here, we thought, the characteristics of 3D images in terms of sensory perception would resonate with our core concept by finding meaningful ground within the social reality of MipoDalmaji, and possibly turn the film into an emotional and poetic journey through this transforming area. 


\subsection{Narrative and Form}

Narratively, the film is anchored by the presence of a foreigner, whose arrival in the neighborhood loosely evokes the 'stranger coming into town' archetype of the Western genre - an influence which actually served as visual reference to the camera team for shots composition and framing. Equipped with a Super $8 \mathrm{~mm}$ handheld camera, the foreigner captures images of the area, which directly mirrors our own filmmaking process but imparts it a fictional veneer. Eventually revealed at the end, his trembling black-and-white images completely oppose the stable colored 3D images: this shocking contrast highlights the technological leap between film stock and digital cinema, as well as their profoundly ambivalent qualities.

Meanwhile, social context is provided by an encounter with a local resident, Mr. Youngjoon Kim, who is a café owner, a curator at the Museum of Contemporary Art Busan (MOCA BUSAN) and an artist himself. His firsthand testimony on the changes in Mipo-Dalmaji doubles as the voice-over narration of the film, through which it achieves documentary veracity.

As a hybrid docufiction, The Old, the New and the Other invokes a series of traditional oppositions: old/new, past/present, city/nature, public/private, familiar/other, film/digital, 2D/3D... In closing, a quote from Gilbert $\mathrm{K}$. Chesterton, found on display in one of the many cafés of the area, acts both as the moral of the story and as our personal commentary: "The tourist sees what he has come to see" [11]

\subsection{Making of The Old, the New and the Other}

Principal photography took place on Saturday September 25th and Sunday September 26th, with additional photography on Tuesday October 26th to shoot extra Super $8 \mathrm{~mm}$ images. The whole film was shot on locations around the Mipo harbor and village, along the Dalmaji hill, by the Haeundae Blueline Park station, and at the BUSAN X the SKY observatory on top of the main LCT Tower. Several local restaurants and cafés owners/managers granted us access to their facilities: Café Rabbit, Solmaru, Café Montée 104 and Edge 993 (Fig. 2).

The technical specificities of the camera equipment, which was provided by the Seoul-based company Dike Co. Ltd., made it so that most locations had to be accessible by car, necessary to power the double-lenses camera, the two recorders, and the control monitors. Indispensable, but demanding and conspicuous, this set-up betrayed the original documentary aspiration of the project but allowed for a more focused and precise mise-en-scène and team dynamic on set.

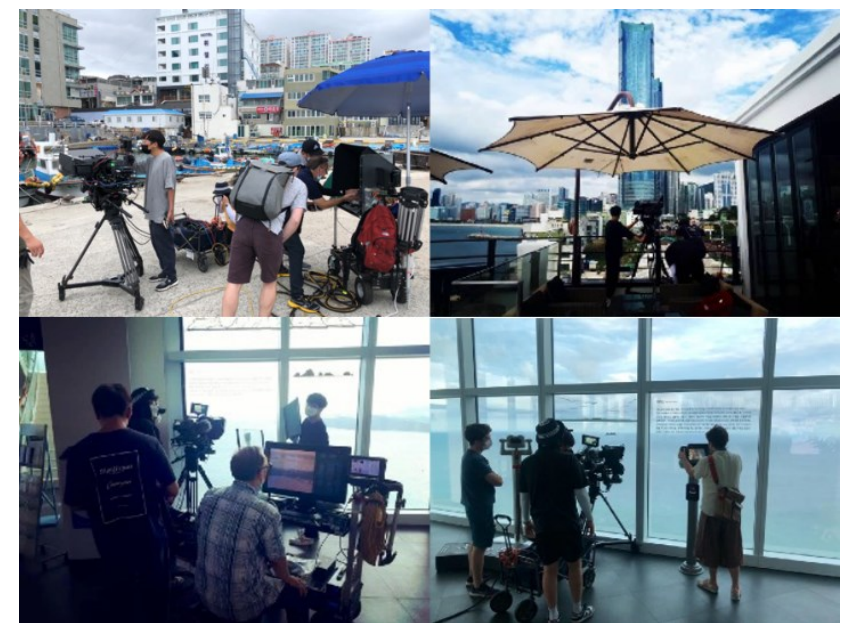

Fig. 2. Stills from the shooting of The Old, the New and the Other.

The most visible object in Haeundae's landscape, and the topic of most anger and controversy surrounding the redevelopment of the area, LCT Tower seemed like a natural destination for the film's narrative - its belly of the beast, its eye of the storm, its end of the line. The film, however, circumvents easy criticism. Instead, it uses the digital telescopes found at that location as a way to conclude its narrative arc in a more surprising fashion: as an open-ended loop imbued with mystery and ambiguity.

The post-production process necessitated several careful steps, particularly in regards to the high-quality and the sheer amount of data of the 4K-3D images, and the technical difficulty to even find a computer capable of handling such sizable video files. Rough editing was therefore first done with low-resolution files (proxy editing), then recreated with the full-quality files identically (RAW editing). As for the Super $8 \mathrm{~mm}$ footage, it was handdeveloped at DCTI, then converted into $4 \mathrm{~K}$ digital files for use in the edit (Fig. 3).

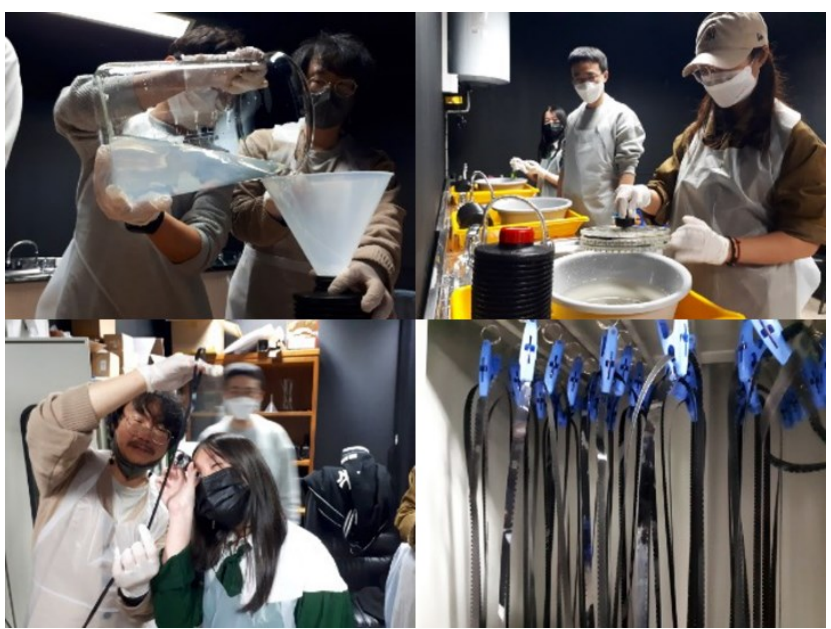

Fig. 3. Super $8 \mathrm{~mm}$ footage manual development for The Old, the New and the Other. 


\subsection{Technical Analysis}

\subsubsection{Background of the Project}

ETRI develops and researches a new broadcast standard for high-quality user-selective UHD stereoscopic media service platform. The standard allows to simultaneously transmit 2D and 3D version of ultra-high definition video content. (Fig. 4)

The purpose of this pilot project is to create a piece of artistic audiovisual content suitable to test the transmission pipeline and quality of the new broadcast standard. As partner of the Busan branch of ETRI, the local film industry cooperates to produce the pilot content with contemporary images.

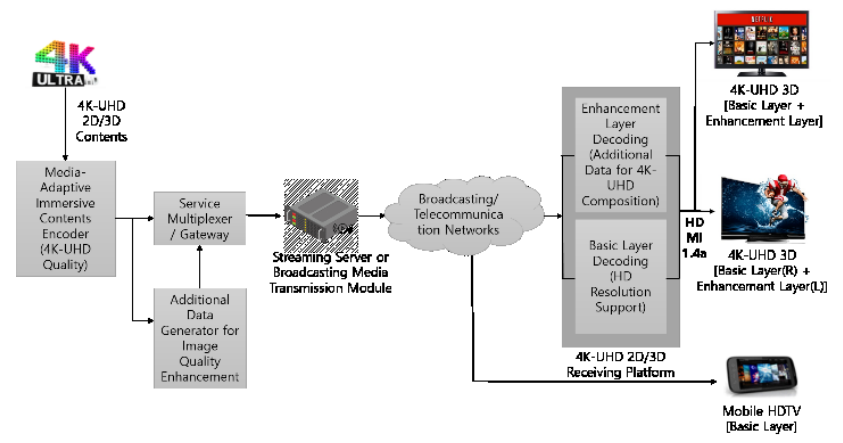

Fig. 4. Concept Diagram of User-Selective UHD Stereoscopic Media Service Platform of the ETRI.

\subsubsection{Technical Specifications}

As technology progresses technical standards evolve. The broadcast industry has accomplished large steps in the past decades moving from standard definition to high definition and ultra-high definition as well from analogue to digital (Table 1).

The pilot film matches the latest technical broadcast production standards for UHDTV. This ensures that the new broadcasting pipeline can be evaluated using most up to date audiovisual production technologies.

Table 1. Specifications of SD/HD/FHD/UHD.

\begin{tabular}{|c|c|c|c|c|c|c|}
\hline & $\begin{array}{c}\text { Aspect } \\
\text { Ratio }\end{array}$ & $\begin{array}{c}\text { Width } \\
(\mathrm{px})\end{array}$ & $\begin{array}{c}\text { Height } \\
(\mathrm{px})\end{array}$ & fps & Color & SMPTE \\
\hline SD & $4: 3$ & 720 & 576 & $50 \mathrm{i} / 60 \mathrm{i}$ & $8 \mathrm{bit}$ & Rec.609 \\
\hline HD & $16: 9$ & 1280 & 720 & $50 \mathrm{p} / 60 \mathrm{p}$ & 8 bit & Rec.709 \\
\hline FHD & $16: 9$ & 1920 & 1080 & $50 \mathrm{i} / 60 \mathrm{i}$ & 8 bit & Rec.709 \\
\hline $\begin{array}{c}4 \mathrm{~K} \\
\text { UHD }\end{array}$ & $16: 9$ & 3840 & 2160 & $50 \mathrm{p} / 60 \mathrm{p}$ & $10 \mathrm{bit}$ & Rec.2020 \\
\hline
\end{tabular}

\subsubsection{Equipment}

The camera used for the pilot film production is Sony Venice Digital Cinema Camera (Fig. 5).

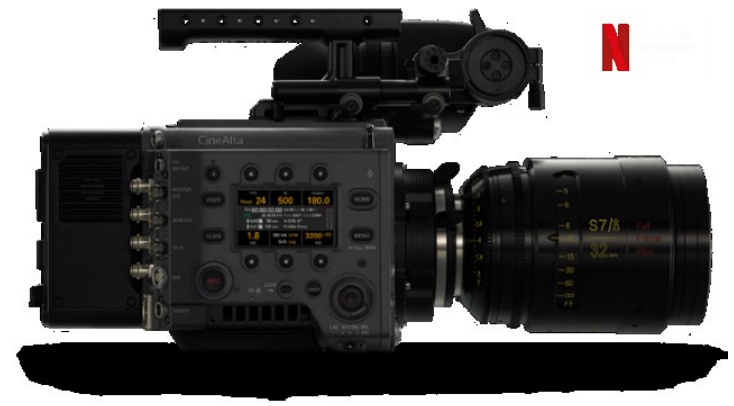

Fig. 5. Sony Venice Digital Cinema Camera.

The camera is used for modern digital cinema productions and high-quality television dramas. The camera allows recording raw camera sensor data with a color depth of 16bit and a dynamic range, that can be used for HDR images.

Stereoscopic content uses generally two video streams: one for the left and another one for the right eye. For production of live stereoscopic content usually two identical cameras are used with the same technical specifications. During production stereoscopic effects can be controlled by changing IAD (interaxial distance) and HOT (horizontal image translation).

In order to control such parameters on the set, professional production recur to beam splitter rigs. Two camera are aligned in an angle of 45 degrees filming across a semi-transparent mirror. Remote control systems allow to control most parameters in real-time. During the production of the pilot film, a Freestyle Rig by $\mathrm{P}+\mathrm{S}$ Technik (Fig. 6) was used.

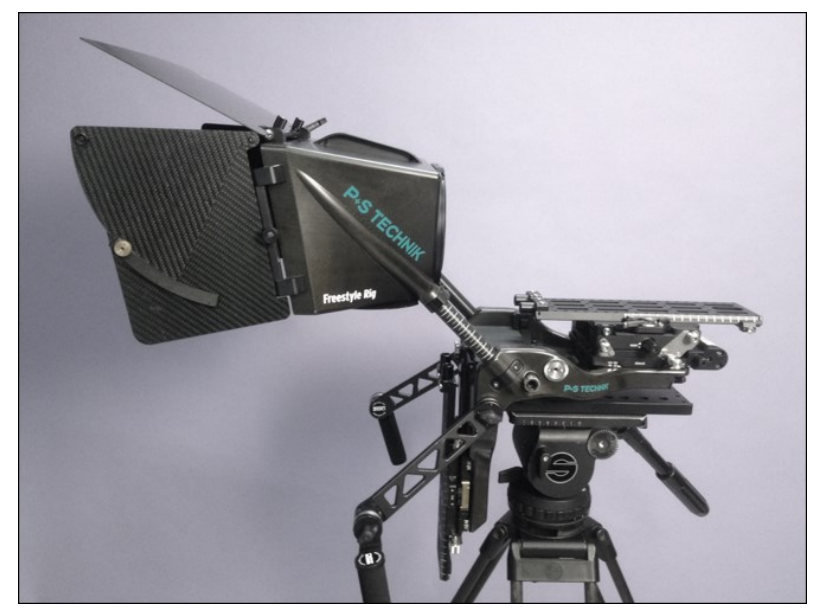

Fig. 6. 3D Freestyle Rig of $\mathrm{P}+\mathrm{S}$ Technik.

For stereoscopic 3D productions, the two cameras need to be geometrically aligned and matched. Such matching can be controlled using computer vision. During the production of the pilot film, a Stereo Image Processor (SIP) from 3Ality Technica (Fig. 7) was used. 
colorspace Rec.2020 with 10bit. Lookup tables (LUTs) (Fig. 8) are used to match the transposition of gamut and colorspaces. Additionally, different looks can be created to emulate film styles or to create the desired artistic effects. LUTs are also applied for monitoring to correct and to calibrate images for different devices.

Fig. 7. Stereo Image Processor 2101 (SIP-2101) of 3Ality Technica

\subsubsection{Recording}

During the 3D Production, the two Sony cameras are synchronized with genlock and timecode in order to create matching image files for the right and for the left camera. These two settings make sure right and left images are recorded simultaneously without any temporal artifacts. Among the possible recording formats as master (RAW) and proxy (as shown in Table 2).

Table 2. Specifications of Master \& Proxy

\begin{tabular}{|c|c|c|}
\hline Type / Format & MASTER / RAW & PROXY / MOV \\
\hline Color & 16bit & $10 \mathrm{bit}$ \\
\hline Frame & UHDTV & HDTV \\
\hline Codec & X-OCN-ST & ProRes422HQ \\
\hline mins & 65 & 65 \\
\hline Streams & 2 & 2 \\
\hline Total mins & 130 & 130 \\
\hline Datarate Single & $206,25 \mathrm{MB} / \mathrm{s}$ & $55,00 \mathrm{MB} / \mathrm{s}$ \\
\hline Datarate Total & $412,50 \mathrm{MB} / \mathrm{s}$ & $110,00 \mathrm{MB} / \mathrm{s}$ \\
\hline Storage TB & $3.217,50$ & 858,00 \\
\hline
\end{tabular}

\subsubsection{Editing}

During the editing process, the stereoscopic images are synchronized by their timecode. Proxy clips are edited for faster preview and display on available HDTV via HDMI. The editing involves a preselection of shots and the arrangement of the final timeline containing the narration of the pilot film. In addition to the image, additional effects and sounds can be added to enhance the narration and storytelling.

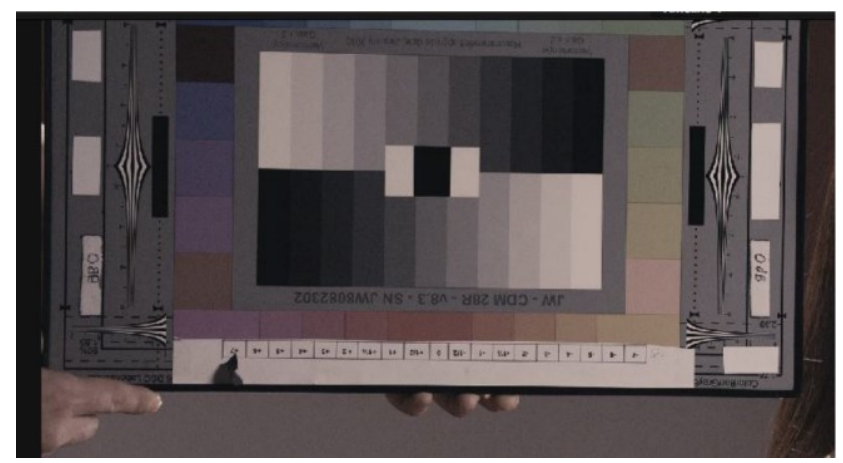

Fig. 8. Lookup Tables (LUTs).

During the editing process, the 16bit color range of the camera sensor has to be matched to the destination

\subsubsection{Mastering}

The final process in the editing is the mastering. In this process, the final settings and corrections are applied. Resolution, file formats and parameters are selected to produce different deliverables. Different formats can be selected for Digital Cinema or UHD television. The mastering process also allows to control and adapt the most important stereoscopic adjustments. It is usually the last step of the production.

The last step of mastering is to render the finished pilot film is rendered in the delivery format:

[Video] 10bit, ProRes 422 HQ (FOURCC = UYVY), $60 \mathrm{fps} / \mathrm{L} / \mathrm{R}$ (left \& right images in separate files and full resolution), uncompressed .MOV file (4K, 3840x2160p)

[Audio] 16bit 48,000kHz PCM

The format is commonly accepted as professional deliverable and master format with a low compression and color subsampling suitable for high-quality broadcast productions.

\section{DISCUSSION}

Watching a film in theater is a full-body experience, even though it normally only requires vision and hearing. Hence the various experiments throughout cinema history which have attempted to involve the three other senses: smell, taste, touch. Yet, stereoscopic 3D cinema remains the one true haptic illusion - the one that tricks people into actively trying to reach for it... or flee from it.

When 3D was exciting and new, it was also terrifying. At early 3D demonstrations, the Associated Press reported, "Spectators ducked as steel balls, apples, pears, and a tray of bottles shot out from the screen." As actor Robert Stack reminisced to the Associated Press, at the premiere of Bwana Devil (1952), "People jumped up from their chairs and ran screaming out of the theater... There was a long tracking shot of a train coming around a corner, then coming directly toward the camera. It looked as though it was going to run over everybody in the theater." It wasn't the first time a cinematic train had terrified audiences. One of the very first films - The Arrival of a Train (1895), directed by the Lumière brothers - showed a locomotive coming straight at the camera. It was ordinary $2 \mathrm{D}$, but 
viewers were still getting used to watching movies at all. They thought the train was going to plow right into them. Now, imagine seeing that in $3 \mathrm{D}$ for the first time, and it makes sense why audiences freaked out [12].

While 3D in commercial cinema may seem out-offashion, the technique itself remains a tool that any filmmaker can choose to employ for its aesthetics and its immersive potential. Technically, it is possible to screen and watch The Old, the New and the Other in 2D - any 3D film can. But doing so would literally rob the film of one dimension. Imagine if you become vision or hearingimpaired: your relation to the world wouldn't just be limited, it would be amputated. A similar impression manifested when we first got used to watching the low-resolution 2D footage in pre-editing and later to watching it in full-quality 3D: it was like discovering a new sense. Shifting back to watching it in $2 \mathrm{D}$, since then, has always felt incomplete.

This is why we became so convinced, and a bit obsessed, by the idea that inserting the footage shot in Super $8 \mathrm{~mm}$ would highlight the 3D footage by sheer contrast, not just in terms of film/digital and black-and-white/colors, but also because the audience suddenly get exposed to a few flat images within a film designed for 'depth'. What happens then, in terms of physical sensation and spatial perception? More importantly: will that help the audience connect to the character emotionally?

If anything, this experience reminded us of the importance of story: what format and choices does a story require? What mise-en-scène treatment does it call for? Given the right story and the right project, we would gladly direct in stereoscopic 3D again with the benefit of what we learned and felt by making The Old, the New and the Other.

\section{CONCLUSION}

The stereoscopic cinema, which was attempted from the early days of cinema history, entered its second heyday since the 2000s, after the 'Golden Age' of 3D cinema in the $1950 \mathrm{~s} \sim 1960$ s and its renaissance in the mid-1970s to the mid-1980s. The stereoscopic media technology that has been researched and developed so far will be combined with new technologies such as high-speed Internet communication, IoT, interactive media, AR, VR, MR, XR, Metaverse and $\mathrm{AI}$ that are rapidly developing, so that the existing cinematographic audience experience will be abruptly converted. And the stereoscopic media content requires a new perspective different from the principle of 2D media content in terms of creation and acceptance. Therefore, a new epistemological paradigm is required in existing academic fields such as film studies and media theory. Media is converged and platforms (devices) are diverged. And the boundary between the real and the virtual has collapsed. In creation and acceptance, separation and combination proceed at the same time, the distinction between local and global has become meaningless by virtual reality, and technology and art face the task of consilience and convergence. Paradigms of traditional perspectives on technology and art will require new perspectives to be validated. Stereoscopic media will find a new trajectory in the field of 'realistic and immersive media', an umbrella term that encompasses VR, AR, MR, XR, AI, and the Metaverse.

This paper examined the technical and aesthetic issues of stereoscopic 3D film production from the perspective of today's emerging realistic and immersive media through a concrete case study along with a brief history of stereoscopic media and 3D cinema and the major related researches. In the field of 3D cinema, 3D image technology, and even realistic and immersive media, new attempts and experiments have been being actively conducted in various areas such as media, platforms, contents, and devices. The 3D pilot film presented as a case study was produced to provide basic data related to creation and acceptance for the future research and development of user-selective UHD stereoscopic media service platform in this paper.

\section{Acknowledgement}

This work was supported by Electronics and Telecommunications Research Institute (ETRI) grant funded by the Korean government [21AR1210, Research on 3D Film \& Moving Image Types, Audience Experience, and Technological Elements for 'User-Selective UHD Stereoscopic Media Service Platform' R\&D and Diffusion of Research Results]. If you intend to utilize the contents of this work, you must disclose that the research was funded by Electronics and Telecommunications Research Institute (ETRI).

\section{REFERENCES}

[1] K. Nakayama and S. Shimojo, "Da Vinci Stereopsis: Depth and subjective occluding contours from unpaired image points," Vision Research, vol. 30, no. 11, pp.1811-1825, 1990.

[2] http://www.3dfilmarchive.com/first-3-d-feature (accessed on 20 November 2021).

[3] F. Devernay and P. Beardsley, "Stereoscopic Cinema," in R. Ronfard and G. Taubin (eds.), Image and Geometry Processing for 3-D Cinematography, Berlin; Heidelberg, Springer, p. 13, 2010.

[4] R. Spottiswoode, N. Spottiswoode and C. Smith, "Basic Principles of the Three-Dimensional Film," SMPTE Motion Imaging Journal, vol. 59, no. 4, pp. 249-286, Oct. 1952. 
[5] F. Devernay and P. Beardsley, "Stereoscopic Cinema," in R. Ronfard and G. Taubin (eds.), Image and Geometry Processing for 3-D Cinematography, Berlin; Heidelberg, Springer, p. 13, 2010.

[6] L. Lipton, Foundations of the Stereoscopic Cinema: A Study in Depth, Van Nostrand Reinhold, 1982.

[7] F. Devernay and P. Beardsley, "Stereoscopic Cinema," in R. Ronfard and G. Taubin (eds.), Image and Geometry Processing for 3-D Cinematography, Berlin; Heidelberg, Springer p. 14, 2010.

[8] B. Mendiburu, 3D Movie Making: Stereoscopic Digital Cinema from Script to Screen, Focal Press, 2009.

[9] Byeong-Cheol Kim, "A Study on the Technique of the 3D Stereoscopic Cinema," Journal of Korea Multimedia Society, vol. 16, no. 8, pp. 994-1004, Aug. 2013.

[10] A. Hamacher, "Stereoscopy in Virtual Reality," International Journal of Engineering Trends and Technology (IJETT), vol. 69, no. 6, pp. 126-130, June 2021.

[11] G. K. Chesterton, The Temple of Silence and Other Stories (1929), recited in I. Stavans and J. Ellison, Reclaiming Travel, Duke University Press, 2015.

[12] Z. Z. Dean, "What It Was Really Like To Watch The First 3D Movie In Theaters," Looper, Mar. 2, 2021; https://www.looper.com/345970/ (accessed on 20 November 2021).

\section{Authors}

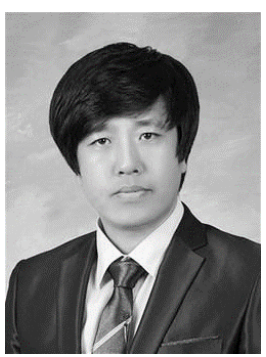

Minchol Cha is professor at Dong-eui University (Department of Film Studies) \& director of the Busan International Short Film Festival (BISFF). He has been director of the Busan Independent Film Association. After his studies at Hankuk University of Foreign Studies (B. A. in French Language \& Politics), he moved to France, where he studied cinema, cultural policy and documentary at the University of Paris 3 (M. A.), Sciences Po. Paris (M. A.), the University of Evry-Val-d'Essonne (Master Pro) and the University of Grenoble 3 (Doctorate). He published The Documentary (CommunicationBooks) in 2014. He translated FilmCraft: Directing by Mike Goodridge into Korean in 2018. He also directed documentary films such as Journey to Beethoven Sonatas (2007), L'accompagnement (2008), Mr. John's Choice (2010), Portrait of Merchants (2010). His main research fields are documentary cinema, experimental cinema, interactive cinema, and transmedia.

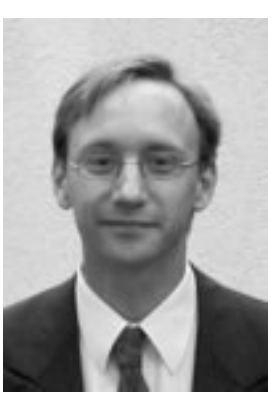

Alaric Hamacher is professor for 3D Contents and Virtual Reality in the Graduate School of Smart Convergence, Kwangwoon University \& programmer of the Busan International Short Film Festival (BISFF). Graduated in directing and producing from the Academy for Television and Cinema Munich, he holds a MA in Film Sciences from Paris VII University. $\mathrm{He}$ received his $\mathrm{Ph}$. D. in Computer Science at Gachon University. He directed stereoscopic 3D on many 3D commercials and corporate movies. His present research focusses on 3D and Augmented and Virtual Reality.

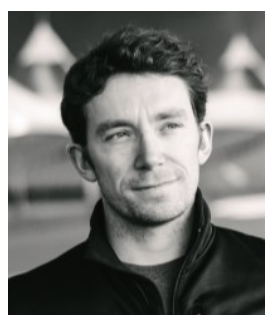

Sébastien Simon is guest professor for Animation \& VFX Major in International College, Dongseo University, film director and programmer of the Busan International Short Film Festival (BISFF). Graduated in film editing from the École Supérieure libre d'Études Cinématographiques (ESEC), he received his BA \& MA in cinema studies from Paris I University. He has directed award-winning films such as The Troubled Troubadour (2016), One-minded (2014) as well as the stereoscopic 3D pilot film presented in this paper. His present research focusses on film directing, film editing, cinematography, 3D and VR. 